\title{
Risk of penstock fatigue in pumped-storage power plants operating with variable speed in pumping mode
}

\author{
Guillermo Martínez-Lucas , Juan I. Perez-Díaz, Manuel Chazarra, Jose I. Sarasúa , \\ Giovanna Cavazzini , Giorgio Pavesi , Guido Ardizzon
}

Keywords:

Failure analysis

Power plant

Fatigue life

Structural failure

Simulation test

\begin{abstract}
A B S T R A C T
The upgrade of a pumped-storage power plant (PSPP) to allow variable speed operation offer several advantages in pumping and generating modes. However, in pumping mode at part load, both pressure and torque pulsations develop in the pump turbine runner. This paper evaluates the risk of fatigue damage in the penstock of a variable-speed PSPP due to the propagation of the pressure pulsations developing in the pump turbine runner at partial load in pumping mode. For that purpose, a simulation model of a variable-speed PSPP has been developed. The pressure and torque pulsations are generated each from a different set of sinusoidal functions calibrated from the results of a Computational Fluid Dynamic model, which was in turn validated from experimental data. A Monte Carlo simulation has been performed considering different temporal gaps between the sinusoidal functions reproducing the pressure pulsations in one and another pump turbine. The number of stress cycles that may cause fatigue damage in the penstock has been obtained from the results of the simulations and the fatigue curves defined in the Eurocode, and then transformed into the maximum number of hours per year the PSPP can operate at partial load in pumping mode to avoid fatigue damages.
\end{abstract}

\section{Introduction}

Variable speed operation offer a lot of advantages for a pumpturbine operating both in generating and pumping mode, i.e. the possibility of an almost instantaneous active and reactive power control, higher efficiency or wider operating range [1].

Nevertheless, at part load in pumping mode, reversible pumpturbine machines suffer from unstable behaviour related to a strong fluid-dynamical interaction between rotor and stator parts that causes the development of unsteady phenomena [2]. The pressure and torque pulsations associated with these unsteady phenomena might propagate both along the power plant conduits and to the electrical grid [3]. The torque pulsations might in turn have a certain influence on the power quality and, as a consequence, affect the design and cost of the converter filters. The propagation of pressure pulsations might cause fatigue in the penstock and, as a consequence, reduce the power plant lifetime or require a higher investment [4]. Material fatigue is a phenomenon of extreme importance recognised as one of the major causes of destruction of materials. In some cases, long structures such as penstock in hydropower plants can suffer serious damages caused by a sudden rupture due to fatigue effects [5].

Fatigue damages in hydropower plant conduits have been barely addressed in the scientific literature. In Ref. [6] the authors describe a detailed integrity assessment of a riveted penstock in a hydroelectric power plant, and conclude that the possibility of a fast fracture event in this particular penstock is remote. In Ref. [7] authors evaluated the risk of fatigue in the penstock of a specific hydropower plant due to the tracking of the secondary loadfrequency control set-point signals, and concluded that the secondary load-frequency control did not cause significant fatigue damages with a proper set of turbine governor parameters. However, fast hydraulic transient phenomena such as the pressure pulsations that develop at part load in pumping mode were not considered in the above-mentioned studies. Ref. [8] is to the author's knowledge the only work where the impact of said pressure 


\begin{tabular}{|c|c|c|c|}
\hline \multicolumn{2}{|c|}{ Nomenclature } & \multirow{3}{*}{$\begin{array}{l}\mathrm{P} \\
\mathrm{p} \\
\mathrm{P}_{\mathrm{p}}\end{array}$} & \multirow{3}{*}{$\begin{array}{l}\text { pressure (m.w.c.) } \\
\text { water pressure } \\
\text { higher amplitude pressure peaks assumed }\end{array}$} \\
\hline a & wave speed $(\mathrm{m} / \mathrm{s})$ & & \\
\hline$A_{U} B_{U} C_{U}$ & & & \\
\hline$A_{-}, D_{H}, C_{H}$ & & & pump flow $\left(\mathrm{m}^{3} / \mathrm{s}\right)$ \\
\hline $\begin{array}{l}\mathrm{A}_{\mathrm{H}, \mathrm{p}} \\
\mathrm{B}\end{array}$ & pressure amplitude for $\mathrm{p} \mathrm{peak} \mathrm{(m)}$ & Q & flow $\left(\mathrm{m}^{3} / \mathrm{s}\right)$ \\
\hline & impeller or guide vane or return channel width & $Q_{d}$ & designed pump flow $\left(\mathrm{m}^{3} / \mathrm{s}\right)$ \\
\hline D & pipe diameter $(\mathrm{m})$ & $\mathrm{Q}_{\mathrm{fp} 1}$ & flow in feeding pipe 1 in steady state $\left(\mathrm{m}^{3} / \mathrm{s}\right)$ \\
\hline $\mathrm{D}_{\mathrm{p}}$ & pump turbine components diameter & $\mathrm{Q}_{\mathrm{fp} 2}$ & flow in feeding pipe 2 in steady state $\left(\mathrm{m}^{3} / \mathrm{s}\right)$ \\
\hline e & conduit thickness (mm) & Qlab & pump flow in laboratory scale $\left(0.0729 \mathrm{~m}^{3} / \mathrm{s}\right)$ \\
\hline $\mathrm{f}$ & Darcy-Weisbach friction factor & $\mathrm{Q}_{\mathrm{p}}$ & pump flow in the PSHP \\
\hline$f_{\mathrm{fp} 1}$ & feeding pipe 1 Darcy-Weisbach friction factor & $\mathrm{q}_{\mathrm{p}, \mathrm{i}}$ & flow at the ith $\Gamma$ element of the penstock (p.u.) \\
\hline$f_{\mathrm{fp} 2}$ & feeding pipe 2 Darcy-Weisbach friction factor & $Q_{p e}$ & flow in penstock in steady state $\left(\mathrm{m}^{3} / \mathrm{s}\right)$ \\
\hline$f_{H, p}$ & pressure frequency for $\mathrm{p} \mathrm{peak}$ & $\mathrm{r} / 2$ & continuous head losses coefficient in pipes (p.u.) \\
\hline$f_{p}$ & penstock Darcy-Weisbach friction factor & $\mathrm{S}$ & pipe section $\left(\mathrm{m}^{2}\right)$ \\
\hline $\mathrm{g}$ & gravity acceleration $\left(\mathrm{m}^{2} / \mathrm{s}\right)$ & $S_{\mathrm{fp}}$ & water speed in the feedings pipes $(\mathrm{m} / \mathrm{s})$ \\
\hline $\mathrm{H}$ & pump head $(\mathrm{m})$ & $\mathrm{S}_{\mathrm{fp} 1}$ & feeding pipe 1 section $\left(\mathrm{m}^{2}\right)$ \\
\hline $\mathrm{H}_{\mathrm{b}}$ & $\begin{array}{l}\text { pressure in the union between feedings pipe and } \\
\text { penstock (m.w.c.) }\end{array}$ & $\begin{array}{l}\mathrm{S}_{\mathrm{fp} 2} \\
\mathrm{~S}_{\mathrm{p}}\end{array}$ & $\begin{array}{l}\text { feeding pipe } 2 \text { section }\left(\mathrm{m}^{2}\right) \\
\text { penstock section }\left(\mathrm{m}^{2}\right)\end{array}$ \\
\hline $\mathrm{H}_{\mathrm{d}}$ & designed pump head (m) & $\mathrm{s}_{\mathrm{p}}$ & water speed in the penstock $(\mathrm{m} / \mathrm{s})$ \\
\hline $\mathrm{H}_{\mathrm{dp}}$ & pressure downstream the pump (m) & $S_{t}$ & Strouhal number \\
\hline$H_{\mathrm{fp} 1, \mathrm{~N}}$ & $\begin{array}{l}\text { pressure in the bifurcation previous point in feeding } \\
\text { pipe } 1 \text { (m.w.c.) }\end{array}$ & $\begin{array}{l}\mathrm{t} \\
\mathrm{t}_{0}\end{array}$ & $\begin{array}{l}\text { time }(s) \\
\text { starting time of speed reduction in pump } 1\end{array}$ \\
\hline $\mathrm{H}_{\mathrm{fp} 1, \mathrm{~N}+1}$ & $\begin{array}{l}\text { pressure at bifurcation measured in feeding pipe } 1 \\
\text { (m.w.c.) }\end{array}$ & $\begin{array}{l}\mathrm{T}_{\mathrm{e}} \\
\mathrm{T}_{\mathrm{w}}\end{array}$ & $\begin{array}{l}\mathrm{L}_{\mathrm{p}} / \mathrm{a} \text {, water elastic time }(\mathrm{s}) \\
\text { penstock water starting time }(\mathrm{s})\end{array}$ \\
\hline $\mathrm{H}_{\mathrm{fp} 2, \mathrm{~N}}$ & $\begin{array}{l}\text { pressure in the bifurcation previous point in feeding } \\
\text { pipe } 2 \text { (m.w.c.) }\end{array}$ & $\begin{array}{l}V \\
V_{f p 1, N}\end{array}$ & $\begin{array}{l}\text { mean flow velocity in conduits }(\mathrm{m} / \mathrm{s}) \\
\text { water speed in the bifurcation previous point in }\end{array}$ \\
\hline $\mathrm{H}_{\mathrm{fp} 2, \mathrm{~N}+1}$ & pressure at bifurcation measured in feeding pipe 2 & & feeding pipe $1(\mathrm{~m} / \mathrm{s})$ \\
\hline$h_{i}$ & $\begin{array}{l}\text { (m.w.c.) } \\
\text { head at the ith } \Gamma \text { element of the penstock (p.u.) }\end{array}$ & $\mathrm{V}_{\mathrm{fp} 1, \mathrm{~N}+1}$ & $\begin{array}{l}\text { water speed at bifurcation measured in feeding pipe } \\
1(\mathrm{~m} / \mathrm{s})\end{array}$ \\
\hline $\begin{array}{l}\mathrm{H}_{\mathrm{i}+1} \\
\mathrm{H}_{\mathrm{i}-1}\end{array}$ & $\begin{array}{l}\text { pressure at the points to the right of } P_{i}(m) \\
\text { pressure at the points to the left of } P_{i}(m)\end{array}$ & $\mathrm{V}_{\mathrm{fp} 2, \mathrm{~N}}$ & $\begin{array}{l}\text { water speed in the bifurcation previous point in } \\
\text { feeding pipe } 2(\mathrm{~m} / \mathrm{s})\end{array}$ \\
\hline $\begin{array}{l}\mathrm{H}_{\mathrm{lab}} \\
\mathrm{H}_{\mathrm{lab}}^{*}\end{array}$ & $\begin{array}{l}\text { pump head in laboratory scale }(6.97 \mathrm{~m}) \\
\text { pressure pulsation in laboratory scale }(\mathrm{m})\end{array}$ & $\mathrm{V}_{\mathrm{fp} 2, \mathrm{~N}+1}$ & $\begin{array}{l}\text { water speed at bifurcation measured in feeding pipe } \\
2(\mathrm{~m} / \mathrm{s})\end{array}$ \\
\hline $\mathrm{H}_{\mathrm{lp}}$ & $\begin{array}{l}\text { pressure at the pump entrance from lower reservoir } \\
\text { (m) }\end{array}$ & $\begin{array}{l}V_{i+1} \\
V_{i-1}\end{array}$ & $\begin{array}{l}\text { water speed at the points to the right of } P_{i}(\mathrm{~m} / \mathrm{s}) \\
\text { water speed at the points to the left of } P_{i}(\mathrm{~m} / \mathrm{s})\end{array}$ \\
\hline $\begin{array}{l}\mathrm{H}_{\mathrm{lr}} \\
\mathrm{H}_{\mathrm{p}}\end{array}$ & $\begin{array}{l}\text { constant level in the lower reservoir }(\mathrm{m}) \\
\text { pump head }(\mathrm{m})\end{array}$ & $\mathrm{V}_{\mathrm{p}, 1}$ & $\begin{array}{l}\text { water speed at bifurcation measured in penstock ( } \mathrm{m} / \\
\mathrm{s})\end{array}$ \\
\hline $\mathrm{H}_{\mathrm{p}, 1}$ & $\begin{array}{l}\text { pressure at bifurcation measured in penstock } \\
\text { (m.w.c.) }\end{array}$ & $\mathrm{V}_{\mathrm{p}, 2}$ & $\begin{array}{l}\text { water speed at after bifurcation point in penstock ( } \mathrm{m} / \\
\mathrm{s})\end{array}$ \\
\hline $\mathrm{H}_{\mathrm{p}, 2}$ & $\begin{array}{l}\text { pressure at after bifurcation point in penstock } \\
\text { (m.w.c.) }\end{array}$ & $\begin{array}{l}\mathrm{V}_{\mathrm{Pi}} \\
\mathrm{x}\end{array}$ & $\begin{array}{l}\text { water speed at the ith sample point along of the pipe } \\
\text { axial distance along the streamline }\end{array}$ \\
\hline $\mathrm{H}_{\mathrm{p} \text { plant }}$ & pump head up-scaled (m) & $\mathrm{z}$ & elevation at any point of the streamline \\
\hline & pump head including pressure pulsations (m) & $\alpha$ & hydraulic similarity factor \\
\hline $\mathrm{H}_{\mathrm{Pi}}$ & pressure at the ith sample point along of the pipe & $\beta$ & hydraulic similarity factor \\
\hline $\mathrm{H}_{\text {plant }}^{*}$ & pressure pulsation up-scaled $(\mathrm{m})$ & $\Delta \mathrm{t}$ & time interval in $\mathrm{MoC}(\mathrm{s})$ \\
\hline $\mathrm{H}_{\text {up }}$ & $\begin{array}{l}\text { pressure at the pump entrance from upper reservoir } \\
\text { (m) }\end{array}$ & $\begin{array}{l}\Delta \mathrm{t}_{0} \\
\Delta \mathrm{x}\end{array}$ & $\begin{array}{l}\text { time gap between both pumps }(\mathrm{s}) \\
\text { length in pipe elements which it has been divided in }\end{array}$ \\
\hline $\mathrm{H}_{\mathrm{ur}}$ & constant level in the upper reservoir (m) & & MoC \\
\hline $\mathrm{L}_{\mathrm{fp}}$ & feeding pipes length (m) & $\lambda$ & Lagrange multiplier \\
\hline $\mathrm{L}_{\mathrm{p}}$ & penstock length $(\mathrm{m})$ & $\lambda_{\mathrm{p}}$ & guide vanes' azimuthally position \\
\hline $\mathrm{n}$ & rotational speed (r.p.m.) & $\rho$ & Water density \\
\hline $\mathrm{n}_{\mathrm{b}, \mathrm{r}}$ & impeller number of blades & $\sigma_{\mathrm{cp}}$ & tangential stress [MPa] \\
\hline $\mathrm{n}_{\mathrm{b}, \mathrm{rc}}$ & return Vane number of blades & $\sigma_{\mathrm{cp}, \mathrm{k}}$ & tangential stress k obtained by RFCM [MPa] \\
\hline $\begin{array}{l}\mathrm{n}_{\mathrm{b}, \mathrm{wg}} \\
\mathrm{N}_{\mathrm{g}}\end{array}$ & $\begin{array}{l}\text { wicket Guide number of blades } \\
\text { probability factor in Monte Carlo simulation }\end{array}$ & $\sigma_{\text {eq,g }}$ & $\begin{array}{l}\text { tangential stress obtained for each time gap g } \\
\text { considered [MPa] }\end{array}$ \\
\hline $\mathrm{N}_{\mathrm{k}}$ & number of times a stress peak is repeated & $\sigma_{\text {eq' }}$ & equivalent tangential stress for each gross head in \\
\hline $\mathrm{n}_{\mathrm{t}}$ & number of segments in which the penstock is divided & & Monte Carlo simulation [MPa] \\
\hline $\mathrm{p}$ & peak number in pulsation generators & & \\
\hline
\end{tabular}

pulsations on the risk of fatigue damage in the penstock of a pumped-storage power plant (PSPP) has been preliminarily evaluated. For that purpose, the authors developed a dynamic simulation model of a variable-speed PSPP operating in pumping mode in unstable operating conditions. A set of sinusoidal functions were proposed in the paper, and integrated in the dynamic simulation model, in order to synthetically generate both pressure and torque pulsations that reproduce the operation of the hydraulic machine 
in its instability region. The proposed sinusoidal functions were validated against the results of CFD (Computational Fluid Dynamics) simulations carried out on a reversible pump-turbine model installed in the Department of Industrial Engineering of the University of Padova (DIE-UP).

The objective of this paper is to evaluate the risk of fatigue damage in the penstock of different variable-speed PSPPs due to the propagation of the pressure pulsations developing in the pumpturbine in unstable operating conditions in pumping mode. This objective is of special interest for existing PSPPs which, maintaining the existing pump turbine runner, will be upgraded to allow variable speed operation, as is the case in some PSPPs recently analysed in the EU FP7 eStorage project [9]. According to the deliverable D4.1 of the said project, a number of pump-turbine units amounting to $34.9 \mathrm{GW}$ will need to be refurbished by 2020 , some of which might be upgraded to allow variable speed operation.

The main reason for upgrading a PSPP to operate with variable speed is that the operation with variable speed allows the PSPPs to provide frequency restoration reserves in pumping mode, and therefore [10] to significantly increase its revenue. In a significant number of European regional power systems (France, Spain and Belgium, among others), frequency restoration reserves are remunerated for two different concepts, reserve availability and delivery [11]. In general, the more reserve capacity, the higher the revenue.

This paper is an extension of the work presented in Ref. [8]. The results of the fatigue analysis presented in that paper indicated that there is no risk of fatigue damage in the penstock of the PSPP analysed therein, as long as the pump-turbines do not operate at part load in pumping mode for a long time. However, authors recognised that evaluating the effect of pressure pulsations in pumped-storage power plants with higher heads than the one analysed in that paper is necessary since unstable operating conditions might have a greater impact. The methodology used in Ref. [8] to analyse the risk of fatigue damage in the penstock of a single variable-speed PSPP is applied here in a number of variablespeed PSPPs with a similar configuration but different design parameters (gross head and life time). A typical PSPP scheme has been assumed, with a single penstock feeding two identical pumpturbines. As an additional contribution to the work developed in Ref. [8], the maximum number of hours per year the PSPP can operate at part load in pumping mode to prevent fatigue damages in the penstock has been obtained from the results of the fatigue analysis, as a function of the PSPP expected lifetime and design gross head. These values have been compared to: a) the number of hours per year in which several PSPPs operating in the Spanish power system provide secondary regulation in generating mode and $b$ ) the number of hours per year in which several theoretical PSPP whose optimum operation has been simulated would operate at partial load in pumping mode [12]; c) the number of hours per year in which two existing variable speed PSPPs provide regulation services both in generating and pumping mode.

The methodology used in Ref. [8] is elaborated in this paper, since for extension reasons it was not fully described in the Hyperbole Conference. The risk of fatigue damage in the penstock is evaluated by means of a Monte Carlo simulation-based fatigue analysis. A dynamic simulation model of the PSPP is developed for this purpose. The pressure and flow transients in the PSPP conduits are modeled by the well-known Method of Characteristics [13]. The pump-turbine operation curves at steady-state (head-flow-rotation speed and torque-flow-rotation speed) and the sinusoidal functions that reproduce the pressure and torque pulsations developing in the pump-turbine at part load in pumping mode were up-scaled by hydraulic similarity, from those calibrated in Ref. [8] against the results of several CFD simulations that were carried out on a reversible pump-turbine model installed in the DIE-UP, in a similar way to [14]. A dynamic simulation model of the DIE-UP test rig has been developed for calibration purposes.

The paper is organised as follows. In section 2, the validation of the CFD model and the CFD simulations carried out on the pumpturbine model of the DIE-UP are summarised. In section 3 , the DIE-UP test rig and its simulation model are presented, and the calibration of the pressure pulsations generators is reported. In section 4, the scheme of the analysed PSPP is described and the PSPP simulation model is explained in detail. The fatigue analysis is carried out in section 5. Finally, section 6 contains the conclusions reached in this study.

\section{CFD simulations}

Numerical analyses were carried out on the first stage of a reversible pump-turbine installed in the Laboratory of Hydraulic Machines of the Department of Mechanical Engineering of the University of Padova (Fig. 1). The pump-turbine consists of a sevenblade 3D impeller coupled with a vaned diffuser and a vaned return channel, reproducing the scaled down first stage of a two-stage reversible pump-turbine. The main geometrical characteristics of the reversible pump-turbine are reported in Table 1.

The peculiarity of this reversible pump-turbine is the possibility of modifying not only the opening angle. of the wicket guide vanes but also the relative azimuthal position of the wicket gate vanes with respect to the return channel blades. In particular, being fixed the wicket gate angle $\alpha_{3 b}$, the whole wicket gate cascade can rotate, as a rigid system, of an angle $\lambda_{p}$ around the pump-turbine axis, modifying in this way the azimuthal position of the guide vanes with respect to the return channel vanes. Fig. 2 reports the so called "face-to-face" configuration in which the return channel vanes are aligned to the wicket gate vanes $\left(\lambda_{p}=0^{\circ}\right)$. The rotation of the whole system allows to modify this azimuthal position up to the maximum misalignment of $\pm 8^{\circ}$ from the face-to-face configuration. In the considered analyses, the wicket gate vanes were +8 out of alignment with an opening angle of $18^{\circ}$, corresponding to a radial gap between their leading edge (in pumping mode) and the impeller tip of $10.5 \mathrm{~mm}$ (5.25\% of the impeller radius).

The entire pump-turbine (inlet duct, impeller, wicket gate vanes, return channel and leakage system) was discretised by means of structural meshes, properly sized and designed to capture unsteady phenomena developing in the unstable operating area of

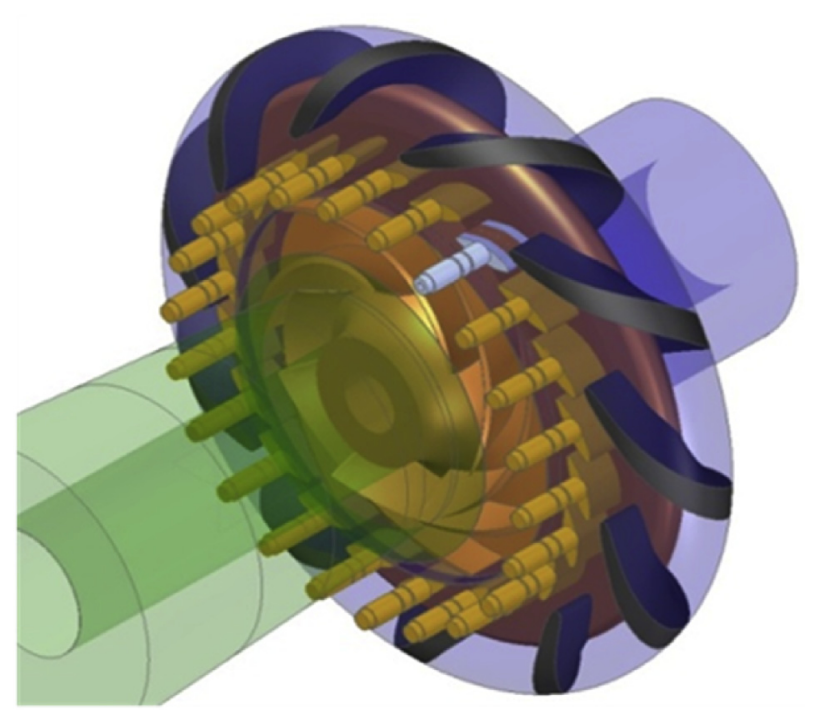

Fig. 1. Three-dimensional scheme of the pump-turbine. 
Table 1

Main geometrical and performance characteristics of the pump-turbine.

\begin{tabular}{|c|c|c|c|c|}
\hline \multicolumn{5}{|l|}{ Impeller data } \\
\hline $\mathrm{D}_{\mathrm{p} 2}(\mathrm{~mm})$ & $\mathrm{B}_{2}(\mathrm{~mm})$ & $\mathrm{n}_{\mathrm{b}, \mathrm{r}}$ & $\beta_{2 b}\left({ }^{\circ}\right)$ & $\phi_{\text {Des }}$ \\
\hline 400 & 40 & 7 & 26.5 & 0.125 \\
\hline \multicolumn{5}{|c|}{ Wicket Guide data } \\
\hline $\mathrm{D}_{\mathrm{p} 3}(\mathrm{~mm})$ & $\mathrm{B}_{3}(\mathrm{~mm})$ & $\mathrm{n}_{\mathrm{b}, \mathrm{wg}}$ & $\alpha_{3 \mathrm{~b}}\left({ }^{\circ}\right)$ & $\lambda_{\mathrm{p}}\left({ }^{\circ}\right)$ \\
\hline 410 & 40 & 22 & $10 \div 30$ & $-8 \div 8$ \\
\hline \multicolumn{5}{|c|}{ Return channel vanes data } \\
\hline $\mathrm{D}_{\mathrm{p} 4}(\mathrm{~mm})$ & $\mathrm{B}_{4}(\mathrm{~mm})$ & $\mathrm{n}_{\mathrm{b}, \mathrm{rc}}$ & $\alpha_{4 \mathrm{~b}}\left(^{\circ}\right)$ & \\
\hline 516 & 40 & 11 & 30 & \\
\hline
\end{tabular}

the pump-turbine with a resulting computation domain of more than 13 million of cells (Fig. 3). More details on the mesh can be found in Ref. [15].

As regards the turbulence model, a Detached Eddy Simulation (DES) model was adopted due to the large flow separations expected at part loads and particularly in the unstable operating area. A fully turbulent boundary layer was assumed on blades and end walls with transient sliding interfaces between stator and rotor blocks. Experimental values of the total pressure were assumed at the inlet boundary condition, whereas at the outlet average static pressure values were combined with an opening condition in the hypothesis of a perturbed flow field.

\subsection{Validation of the numerical model}

To validate the numerical model, the numerical results, obtained by steady simulations carried out at several operating conditions and at a constant rotation rate of $600 \mathrm{rpm}$, were compared with experimental data acquired, according to ISO standards, on the pump-turbine installed in the Laboratory of the DIE-UP [16]. For each operating point, the simulation convergence was achieved after more than 20 impeller revolutions and the numerical results were acquired for a time period equal to five more revolutions.

The comparison with the experimental results showed a good accuracy of the numerical model with a maximum percentage error of $3.84 \%$ in head and a small over-prediction $(\max +1.24 \%)$ in the unstable operating area (Fig. 4).

\subsection{Numerical analysis of a power reduction scenario}

The evolution of the flow field in a power reduction scenario was numerically analysed by means of a transient simulation with time-varying boundary condition. This scenario was reproduced by progressively reducing the impeller rotation rate and by

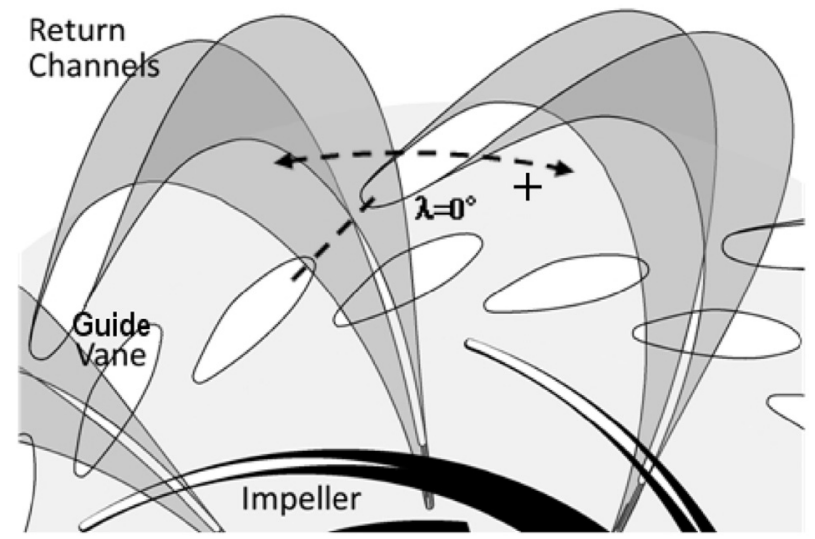

Fig. 2. Face-to-face position of the wicket gate vanes in comparison with the return channel blade $\left(\lambda=0^{\circ}\right)$. simultaneously varying the inlet total pressure and the outlet average static pressure on the basis of the corresponding experimental values at steady conditions.

The initialization was based on the results of the steady simulation at the design flow rate and the impeller rotation rate was assumed to linearly vary from $100 \%(600 \mathrm{rpm})$ to $88 \%$ (530 rpm), corresponding to a power reduction from full load to about $46 \%$ with a ramp rate of $1.5 \%$ (continuous line in Fig. 4 ). In such a scenario, the flow field of the pump-turbine experienced the progressive onset and development of unsteady phenomena, characterised by pressure and torque pulsations more and more intense. More details on the flow field evolution can be found in Ref. [17].

\section{DIE-UP plant description}

A dynamic simulation model of the DIE-UP test rig has been developed in order to reproduce the above described CFD simulation and calibrate a sinusoidal function aiming to reproduce the pressure pulsations that develop in the DIE-UP pump-turbine at part load in pumping mode. Due to the scope of the paper, authors have not considered including in the model the expression which relates the torque to the pumped flow.

The DIE-UP test rig consists of a suction pipe with around $10 \mathrm{~m}$ length, a reversible pump-turbine, and a short impulsion pipe connected to a tank with a spillway (see Fig. 5 and Fig. 6).

The simulation model of the DIE-UP test rig considers an elastic water column in the suction pipe by means of an approach similar to the one used in Ref. [18]. Due to its short length, a rigid water column is considered in the impulse pipe. The flow-head loss function has been obtained by linear regression from the results of the CFD simulations.

The variable speed pump-turbine has been modeled through it operation curve (1) Parameters in expression (1) corresponding to

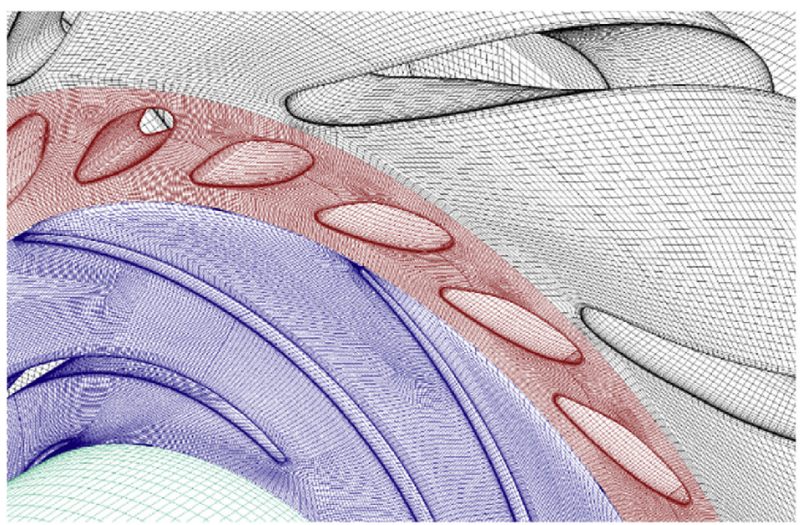

Fig. 3. Detail of the coarse mesh of the numerical model: the rotor-stator interaction area. 


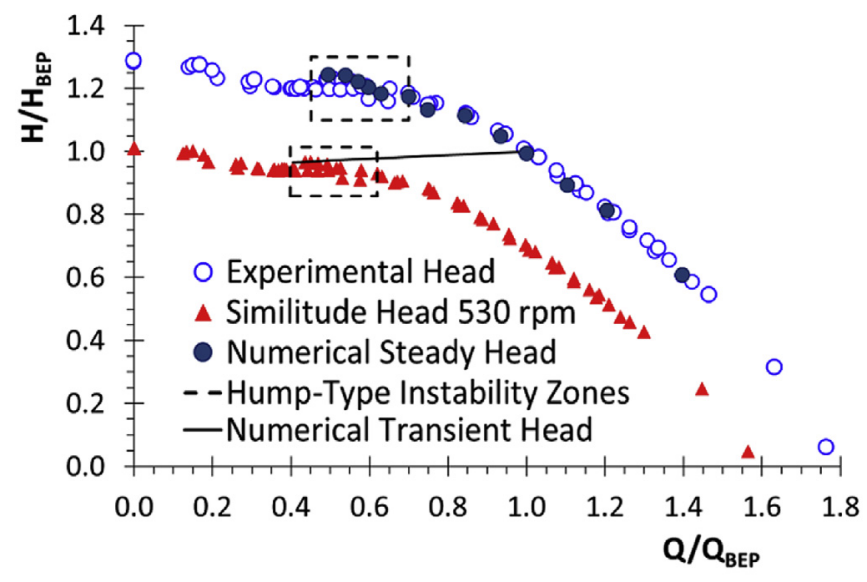

Fig. 4. Head-flow discharge curves at different rotation rates ( $600 \mathrm{rpm}$ and $530 \mathrm{rpm}$ ): comparison between numerical and experimental results.

$n=558 \mathrm{rpm}$ were obtained by linear regression from the results of the CFD simulation. The parameters corresponding to other rotation speeds were then obtained by hydraulic similarity from the previous ones, where $\alpha$ are the hydraulic similarity factors defined in (2).

$H_{p}=\alpha^{2} A_{H}+\alpha B_{H} Q_{p}+C_{H} Q_{p}^{2}$

$\alpha=\frac{n}{558}$

To include the effect of pressure pulsations in the model, a function that synthetically generate pressure $H_{l a b}{ }^{*}$ (3) pulsations has been added [8].

$H_{l a b}^{*}=\sum_{p=1}^{p=P_{p}} A_{H, p}(n) \cdot \sin \left(2 \pi \cdot f_{H, p}(n) \cdot t\right)$

The amplitude $\left(A_{H, p}\right)$ and frequency $\left(f_{H, p}\right)$ in (3) has been obtained from the results of a spectral analysis carried out on the results of the CFD simulation. The results of the CFD simulation have been partitioned into 32 groups, each corresponding to a different range of rotation speeds. For each group, the pressure FFT has been obtained. The $P_{p}$ higher amplitude peaks of the pressure

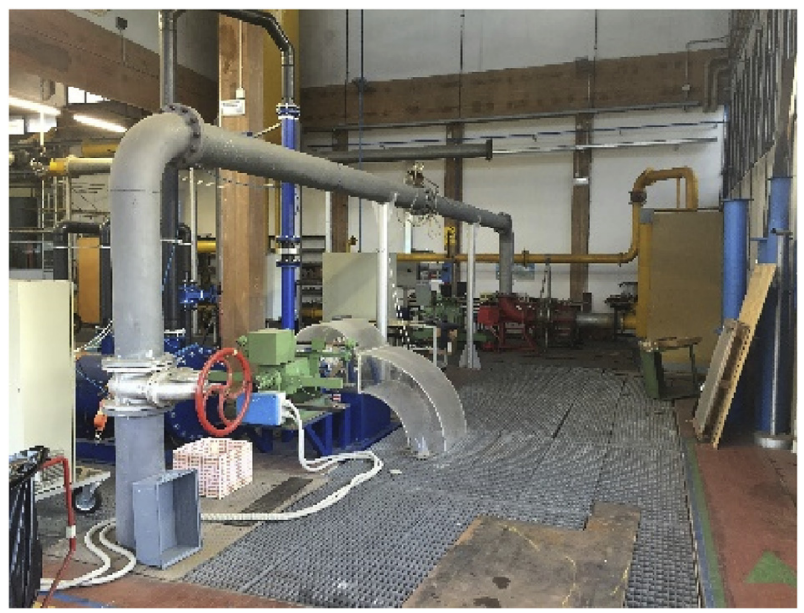

Fig. 5. DIE-UP test rig photography.

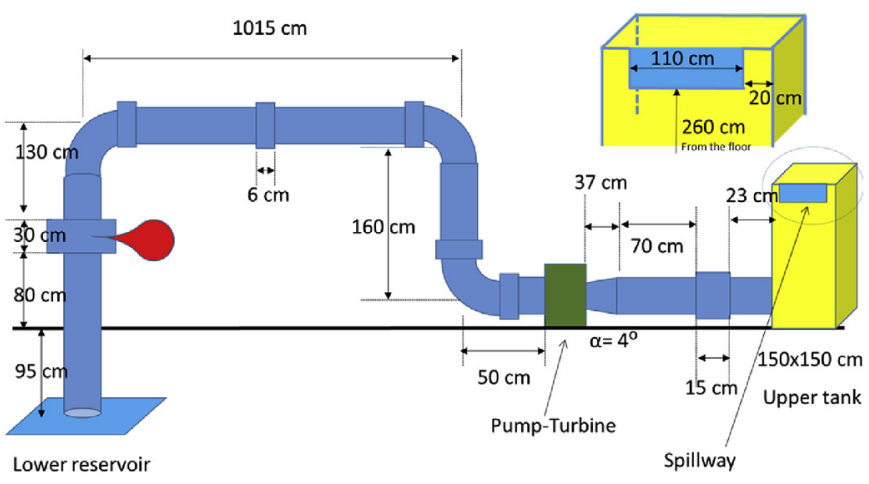

Fig. 6. DIE-UP test rig scheme.

FFT of each group, along with their corresponding frequencies, have been associated to the mean rotation speed of the group. The amplitudes and frequencies of pressure pulsations, corresponding to other intermediate rotation speeds have been obtained by linear interpolation.

The CFD simulation has been reproduced in the simulation model, considering different values of $P_{P}$. As can be seen in Fig. 7a and $b$, both the power spectrum of pressure pulsations and the results of the dynamic simulation model with $P_{p}=6$ matched significantly with those obtained in the CFD simulation.

\section{PSPP description and simulation model}

A typical PSPP scheme (Fig. 8) has been considered which consists of a long penstock that branches into two short feeding pipes, each connected to a variable speed pump-turbine (identical to each other). Each pump-turbine is in turn connected to the lower reservoir through a short draft tube. Different gross heads have been considered in order to study its influence on the risk of fatigue damage in the penstock. The length and water speed of/in the penstock and feeding pipes are the same in all analysed cases (see Table 2). The rated flow of the pump-turbines for each considered gross head has been obtained by hydraulic similarity (4) from the rated flow and head of the DIE-UP pump-turbine.

$Q_{d}=Q_{l a b}\left(\frac{H_{d}}{H_{l a b}}\right)^{3 / 2}$

Due to the short length of the draft tubes, their dynamics and head losses have been neglected. Therefore, $H_{l r}$ and $H_{u p}$ have been assumed equal to zero considering it the reference level (see Fig. 8).

The transient flow in closed conduits is well described by the equations for the conservation of mass and momentum (5) and (6) [13].

$\rho a^{2} \frac{\partial V}{\partial x}+\frac{\partial p}{\partial t}=0$

$\frac{\partial V}{\partial t}+\frac{1}{\rho} \frac{\partial p}{\partial x}+g \frac{d z}{d x}+\frac{f}{2 D} V|V|=0$

Several approaches have been used in the literature to solve (5) and (6). The well-known Method of Characteristics (MoC) is used in this paper to solve (5) and (6), in order to properly capture the propagation of the pressure pulsations developing in the pumpturbine along the PSPP penstock. From the authors' experience, the MoC outperforms the well-known Lumped Parameters approach (LPa) [20-22] for the above purpose (see Appendix).

The MoC approach transforms the water hammer partial 
(a)

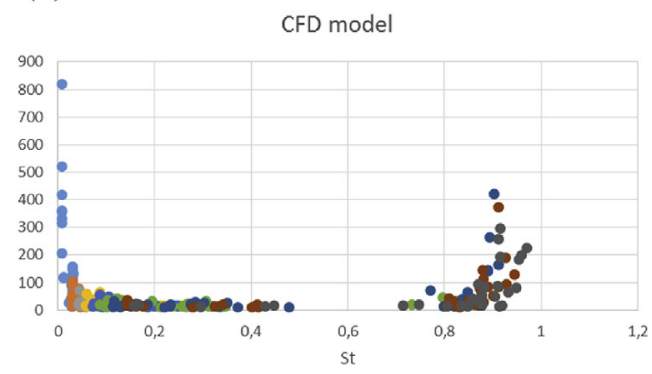

(b)

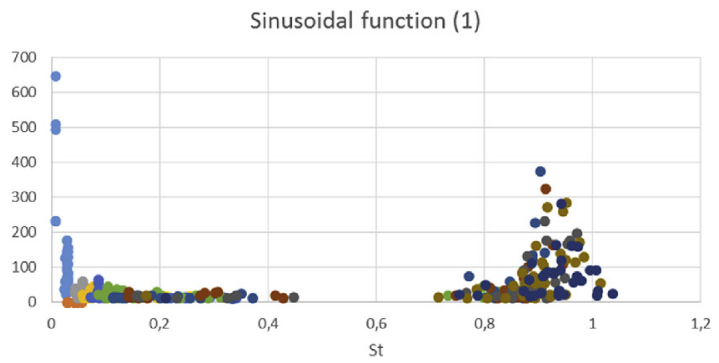

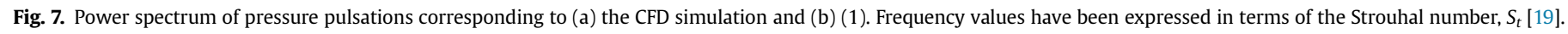
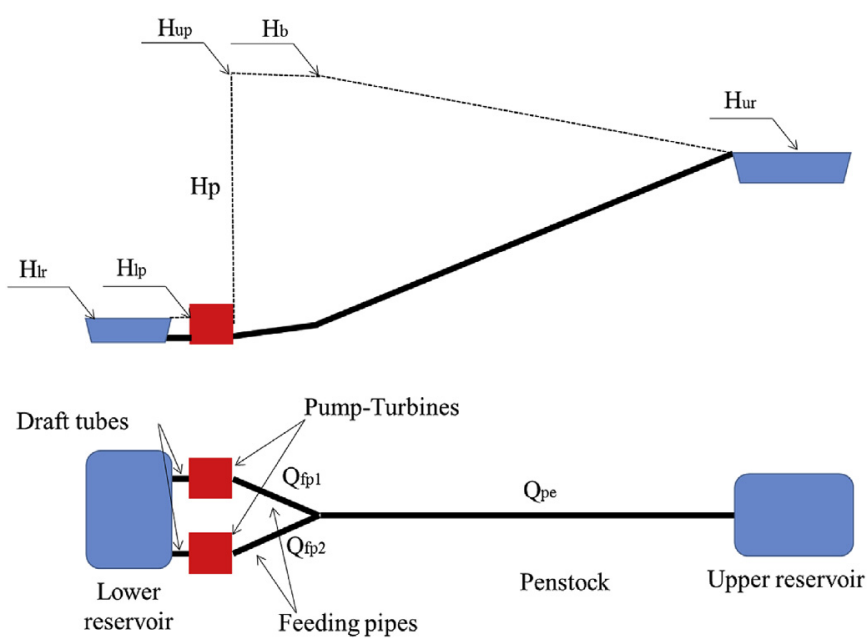

Fig. 8. PSPP scheme.

differential equations (5) and (6) into a system of ordinary differential equations, whose validity is constrained to a set of characteristic curves, by using a linear combination of transient flow equations. Introducing the Lagrange multiplier $\lambda$ in (5) and (6) results expression (7).

$\lambda\left\{\frac{\partial V}{\partial t}+\frac{1}{\rho} \frac{\partial p}{\partial x}+g \frac{d z}{d x}+\frac{f}{2 D} V|V|\right\}+\left\{\rho a^{2} \frac{\partial V}{\partial x}+\frac{\partial p}{\partial t}\right\}=0$

Expression (7) can be rewritten as follows

$\left(\lambda \frac{\partial V}{\partial t}+\rho a^{2} \frac{\partial V}{\partial x}\right)+\left(\frac{\lambda}{\rho} \frac{\partial p}{\partial x}+\frac{\partial p}{\partial t}\right)+\lambda g \frac{d z}{d x}+\lambda \frac{f}{2 D} V|V|=0$

The first term of equation (8) can be expressed as a full derivative considering constraint (9) while the second term of equation (8) can be expressed as a full derivative considering constraint (10).

$\lambda \frac{d x}{d t}=\rho a^{2}$

$\frac{\lambda}{\rho}=\frac{d x}{d t}$

So to satisfy both constraints (9) and (10) it is need that:

Table 2

PSPP parameters.

\begin{tabular}{lllll}
\hline & \multicolumn{2}{l}{ Feeding pipes } & \multicolumn{2}{l}{ Penstock } \\
\hline Fixed parameters & $\mathrm{L}_{\mathrm{fp}}$ & 50 & $\mathrm{~L}_{\mathrm{p}}$ & 2000 \\
& $\mathrm{~S}_{\mathrm{fp}}$ & 5 & $\mathrm{~S}_{\mathrm{p}}$ & 5.5 \\
\hline
\end{tabular}

$\lambda= \pm \rho a$

It is possible to use the piezometric head instead of the pressure by recalling that

$p=\rho g(H-z)$

Also note the definition of the wave speed expressed in (13)

$a=\frac{d x}{d t}$

Therefore, the system of equations (14) and (15) describes perturbations movements at speeds $\pm a$ along the positive and negative characteristic lines $\mathrm{C}^{+}$and $\mathrm{C}^{-}[23,24]$.

$C^{+}: \frac{d V}{d t}+\frac{g}{a} \frac{d H}{d t}+\frac{f}{2 D} V|V|=0$

$C^{-}: \frac{d V}{d t}-\frac{g}{a} \frac{d H}{d t}+\frac{f}{2 D} V|V|=0$

Moreover, applying finite difference solution for the MoC expressions (13), (14), (15) along the positive and negative characteristic lines, shown in Fig. 9, reads as follows.

$$
\begin{aligned}
V_{P i}= & \frac{1}{2}\left[\left(V_{i-1}-V_{i+1}\right)+\frac{g}{a}\left(H_{i-1}+H_{i+1}\right)-\frac{f \Delta t}{2 D}\left(V_{i-1}\left|V_{i-1}\right|\right.\right. \\
& \left.\left.+V_{i+1}\left|V_{i+1}\right|\right)\right] \\
H_{P i}= & \frac{1}{2}\left[\frac{a}{g}\left(V_{i-1}-V_{i+1}\right)+\left(H_{i-1}+H_{i+1}\right)-\frac{a f \Delta t}{g} \frac{f D}{2 D}\left(V_{i-1}\left|V_{i-1}\right|\right.\right. \\
& \left.\left.-V_{i+1}\left|V_{i+1}\right|\right)\right]
\end{aligned}
$$

$\Delta x=a \Delta t$

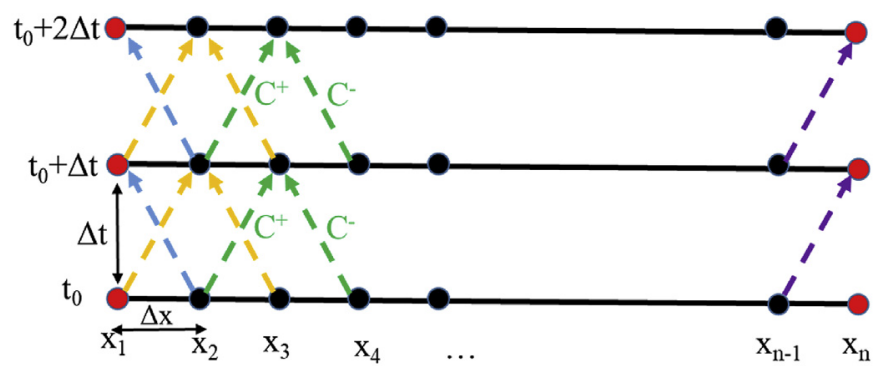

- Boundary condition Interior section

Fig. 9. Positive and negative characteristic lines and Characteristic grid [13]. 
For solving the governing equations the characteristic grid in the $\mathrm{x}-\mathrm{t}$ plane has been considered as shown in Fig. 9.

Expressions (16) and (17) are only valid for the interior points of the solution space. The boundary conditions for (16) and (17) are given by the head in the upstream reservoir $\mathrm{H}_{\mathrm{ur}}$, which is assumed to be constant, and the one right upstream of the pump-turbine $\mathrm{H}_{\mathrm{up}}$, which is given by (24).

In the bifurcation (Fig. 10), flow continuity (19) is required, and neglecting losses, the head at this point must be identical for all branches (20) [25].

$S_{p} V_{p, 1}=S_{f p 1} V_{f p 1, N+1}+S_{f p 2} V_{f p 2, N+1}$

$H_{f p 1, N+1}=H_{f p 2, N+1}=H_{p, 1}=H_{b}$

The pump-turbine operation curves at steady-state (1) and the sinusoidal functions that reproduce the pressure pulsations developing in the pump-turbine at part load in pumping mode (3) have been up-scaled in (21) and (22) by hydraulic similarity [2], from those previously calibrated against the results of the CFD simulation (see section 3).

$H_{p, \text { plant }}=\alpha^{2} \beta^{2} A_{H}+\alpha \beta^{-1} B_{H} Q_{p}+\beta^{-4} C_{H} Q_{p}^{2}$

$H_{\text {plant }}^{*}=\beta^{2} H_{l a b}^{*}(t, n)$

where $\beta$ are the hydraulic similarity factors defined in (23)

$\beta=\sqrt{\frac{H_{b}}{H_{l a b}}}$

Therefore, (24) represents pump-turbine operation curve at variable speed including pressure pulsations at part load.

$H_{\text {p,plant }}^{\prime}=H_{\text {p,plant }}+H_{\text {plant }}^{*}$

The dominant frequencies of the pressure pulsations in the PSPP simulation model have been assumed to be the same as those used in the simulation model of the DIE-UP test rig, thus assuming that the rotation speed of the pump-turbine is the same. As demonstrated in Ref. [26], similar dimensionless amplitude and frequency of the pressure pulsations can be found both in model and prototype turbines, provided that their rotation speed is the same.

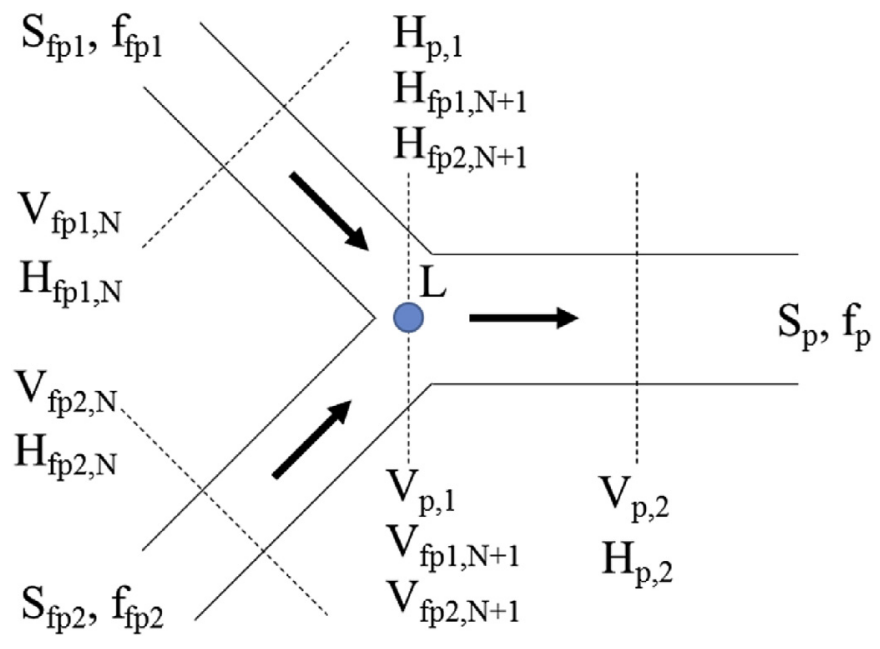

Fig. 10. Bifurcation scheme

\section{Fatigue analysis}

Fatigue damages in conduits are mainly caused by variances in tangential stresses in pipe welds [27]. Tangential stress variances in conduits can be obtained as a function of pressure variances $\Delta \sigma_{c p}=f(\Delta P)$ [7]. Tangential stress in conduits is obtained by expression (25) [28].

$\sigma_{c p}=\frac{P D g}{2 e}$

\subsection{Monte Carlo simulation}

In order to study if the propagation of pressure pulsations may cause damages in the conduits due to the fatigue phenomenon, a linear reduction from 600 to 550 r.p.m. in both pump turbines in pumping mode has been simulated, considering 25 different temporal random gaps $\left(\Delta t_{0}\right)$ between the sinusoidal functions reproducing the pressure pulsations in one and another pump-turbine $\Delta t_{0}$ is obtained randomly between 0.00 and $3.50 \mathrm{~s}$, having every simulation a duration of $20 \mathrm{~s}$.

A set of tangential stresses, with different amplitudes, is obtained from each dynamic simulation in the critical point -bifurcation between the penstock and feeding pipes-. In this stress time series, large cycles are interspersed with small cycles. Therefore, it is necessary to use a counting method that breaks the stress history down into individual cycles which can be summed up into a stress range distribution. For high fatigue cycles, the most frequently methods are the Reservoir Counting Method and the Rain Flow Counting Method (RFCM) [29-31]. As RFCM is the most frequently used cycle counting method in the industry, it is used in this paper. For each simulation, the RFCM allows identifying individual stress cycles from a set of variable amplitude tangential stresses. An equivalent stress has been then obtained using (26) [5] from the twenty [32] higher amplitude stresses obtained by RFCM.

$\sigma_{e q, g}=\sqrt{\frac{\sum_{k=1}^{20}\left(N_{k} \sigma_{c p, k}^{2}\right)}{\sum_{k=1}^{20} N_{k}}}$

Where $\mathrm{N}_{\mathrm{k}}=1$ due to every stress peak occurs only once.

Finally, it is necessary to obtain an equivalent stress for the set of Monte Carlo simulations. This equivalent stress is calculated with a similar expression (27) to the one used previously [5].

$\sigma_{\text {eq }}^{\prime}=\sqrt{\frac{\sum_{g=1}^{25}\left(N_{g} \sigma_{e q, g}^{2}\right)}{\sum_{g=1}^{25} N_{g}}}$

Where $\mathrm{N}_{\mathrm{g}}=1$ due to every temporal gap has been assigned the same probability.

\subsection{Results}

The number of stress cycles that may cause fatigue damage in the PSPP penstock are obtained for each equivalent stress $\sigma_{e q}^{\prime}$ by entering the fatigue curves (Fig. 11) defined in Ref. [32], considering the worst category of welding due to possible imperfections that may take place in some areas of the pipe, as suggested in Ref. [27].

The fatigue analysis was carried out considering different pumped heads. Table 3 summarises the maximum number of stress cycles calculated for each $\sigma_{e q}^{\prime}$ to avoid fatigue damages.

The maximum number of stress cycles shown in Table 3 has been expressed in Fig. 12, in terms of the maximum hours per year 


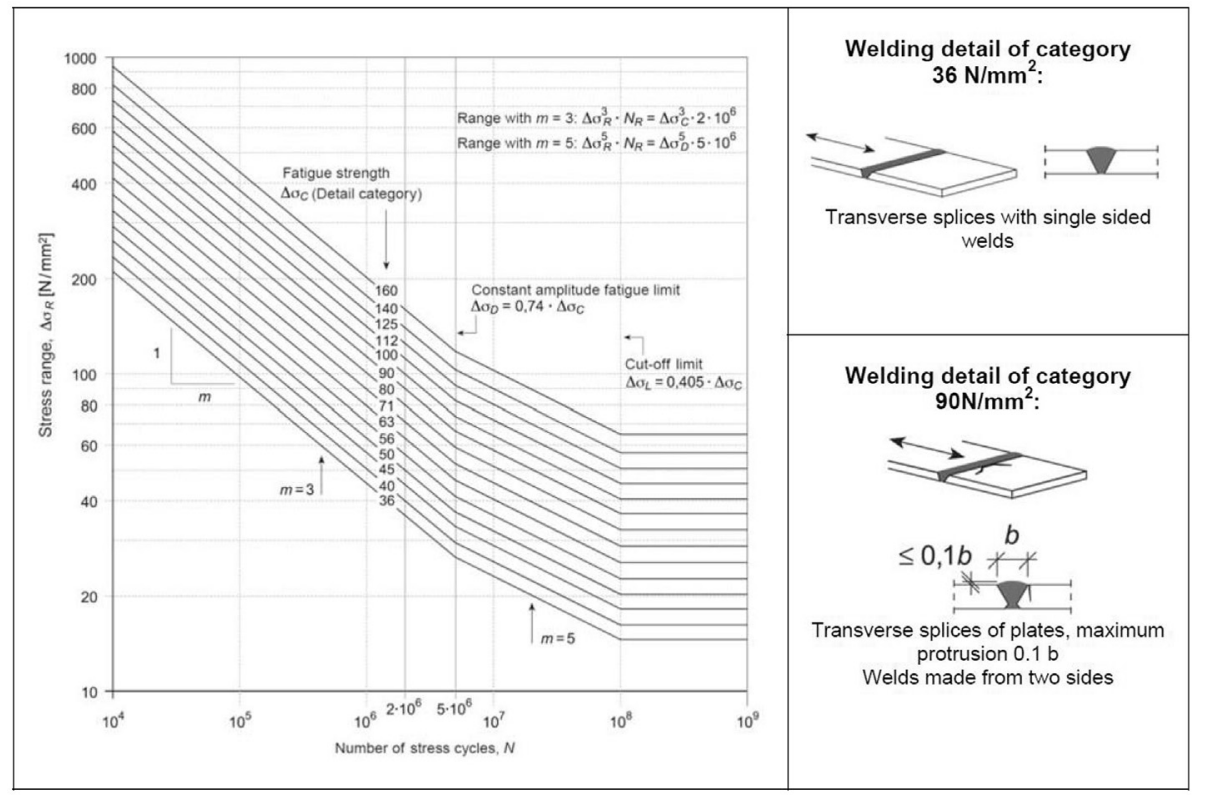

Fig. 11. Fatigue resistance curves for normal stress variations [32].

the PSPP can operate at partial load in pumping mode, considering different power plant lifetimes. Note that it is widely accepted in the technical literature a lifetime of PSPP between 60 years (the reader is referred to [33] or [34], for instance) and 100 years (see for example [35] or [36]).

For this purpose, it has been considered that $\sigma_{\text {eq }}^{\prime}$ occurs every $20 \mathrm{~s}$, which matches the simulation time. Therefore, in an hour in which the PSPP operates at partial load in pumping mode, there would be 180 stress cycles of $\sigma_{\text {eq }}^{\prime}$ MPa.

The maximum number of hours per year at partial load in pumping mode presented in Fig. 12 is compared next to the number of hours per year that i) real PSPPs that are currently operating in the Spanish electricity system, are operated in the secondary regulation service in generating mode, and ii) theoretical PSPPs whose optimal operation has been simulated, are operated at partial load in pumping mode. Note that the real/theoretical PSPPs are equipped with fixed-speed/variable-speed pump-turbine units; therefore, they cannot/can be operated at partial load in pumping mode, respectively. The main goal of the comparison is to discuss if either real PSPPs or theoretical PSPPs are exposed or not to fatigue damage in the penstock, according to the results shown in Fig. 12.

The number of hours per year that each real PSPP operates in the secondary regulation service in generating mode in the period 2010-2015, is presented in Table 4. They are referred to as PSPPs 1-7. Although the hourly schedules of the real PSPPs are publicly available in the information system of the Spanish transmission system operator, the authors prefer not to reveal their names. The number of hours per year in the secondary regulation service in generating mode of the real PSPPs presented in Table 4 corresponds to the number of hours in which the PSPPs were assigned some reserve in the secondary regulation reserve market. ${ }^{1}$ Note that a real PSPP of the Spanish market cannot participate in the said

\footnotetext{
${ }^{1}$ In the secondary regulation reserve market of the Spanish electricity system, the market participants have to fulfil a ratio between the upward and the total reserve. This ratio is typically $45-60 \%$. Besides, the committed reserves must be ready to be used in real time by the transmission system operator, what can lead the plants to operate close to the minimum or the maximum power. However, the percentages of the real-time use of the committed reserves are not publicly available in the Spanish system.
}

market in pumping mode.

There are several PSPPs in the Spanish system that barely operate in the secondary regulation reserve market: PSPPs $2-3$ and 5-7. The main reason for this is the operation strategy of each PSPP, having the possibility of operating in many markets, not only in the secondary regulation reserve market. However, PSPPs 1 and 4 have been operated in the reserve market between 2088-3153 and 438-2579 h per year in the period 2010-2015 (see Table 4), respectively. If a similar operation strategy was followed in pumping mode, the fatigue damage in the penstock would not be discarded. It is important to remark that the gross head of the real PSPPs 1 and 4 are 345 and $980 \mathrm{~m}$, respectively.

The number of hours per year that each theoretical PSPP operates in pumping mode in the secondary regulation reserve market of the Spanish electricity system (hSM) in the period 2013-2015 is presented in Table 5. It is also shown the number of hours out of hSM in which the PSPPs are required by the transmission system operator to be operated at partial load in pumping mode (hSM-pmin), i.e., between the minimum power pmin and pmin +0.15 (pmaxpmin). The theoretical PSPPs are referred to as A, B and C-PSPPs, and come from unpublished results from the authors in collaboration with General Electric, obtained with the optimization model presented [12]. The A/B/C-PSPPs are equipped with two variable-speed pump-turbine units, and can be operated in pumping mode between $59 \% / 59 \% / 82 \%$ and $100 \%$ of the maximum power, respectively.

The results presented in Table 5 are consistent with the operating experience in the Swiss variable-speed PSPP of Grimsel II (head of $400 \mathrm{~m}$ ), which was operated from May 2013 to March 2014 during $3500 \mathrm{~h}$ as a controllable load according to [37], or the German variable-speed PSPP of Goldisthal (head of $302 \mathrm{~m}$ ), which is operated since October 2004 for $19 \mathrm{~h}$ per day for frequency-control purposes in generating and pumping mode according to [38] (assuming $9 \mathrm{~h}$ per day in pumping mode, it means $3285 \mathrm{~h}$ per year).

Besides, the theoretical PSPPs are operated between 676 and $1221 \mathrm{~h}$ per year at partial load in pumping mode (close to the minimum power) according to the assumptions made in Ref. [12] with respect to the percentages of the real-time use of the committed secondary regulation reserves. These results preliminary confirm that fatigue damages in the penstock of PSPPs equipped with variable-speed pump-turbine units are not likely to 
Table 3

Maximum number of cycles to avoid fatigue damages.

\begin{tabular}{lll}
\hline Gross Head $[\mathrm{m}]$ & $\sigma_{\text {eq }}^{\prime}[\mathrm{MPa}]$ & Maximum cycles \\
\hline 500 & 13.89 & $\infty^{\mathrm{a}}$ \\
550 & 16.09 & $60,865,932$ \\
575 & 16.46 & $54,317,643$ \\
600 & 17.66 & $38,195,188$ \\
625 & 19.14 & $25,541,735$ \\
650 & 20.47 & $18,285,665$ \\
675 & 20.67 & $17,413,917$ \\
700 & 22.52 & $11,322,613$ \\
\hline
\end{tabular}

${ }^{\text {a }}$ For $\mathrm{Hb}=500 \mathrm{~m}$ is lower than the minimum stress $(14,57 \mathrm{MPa})$ to consider fatigue damages.

occur according to Fig. 12 (the net head of the A, B and C-PSPPs is $253 \mathrm{~m}$ ). Note that the procurement of the secondary regulation service is different depending on the power system. Therefore, the number of hours per year here presented (hSM and hSM-pmin) could change in other power systems different from the Spanish one. It is important to remark that the results shown in Table 5 for theoretical PSPPs are obtained considering only the participation in the day-ahead energy market and in the secondary regulation service of the Spanish electricity market whereas the real PSPPs also participate, among others, in the intraday market or the tertiary regulation service.

\section{Conclusions}

The risk of fatigue damage in the penstock of a variable-speed pumped-storage power plant due to the propagation of the pressure pulsations originated in the pump-turbine when it operates in pumping mode at partial load has been analysed in this paper by means of a Monte Carlo simulation-based approach. A dynamic simulation model of the PSPP has been developed for the said purpose. The PSPP conduits have been modeled by using the Characteristics Method. The pump-turbine has been modeled through its steady-state operation curves (head-flow-rotation speed) and a sinusoidal function to reproduce the pressure pulsations developing in the pump-turbine runner at partial load. Both the operation curves and the sinusoidal function were up-scaled by hydraulic similarity from those obtained from the results of a CFD simulation carried out on a reversible pump-turbine model installed in the University of Padova.

The Monte Carlo simulations were carried out considering different random temporal gaps in the sinusoidal function that

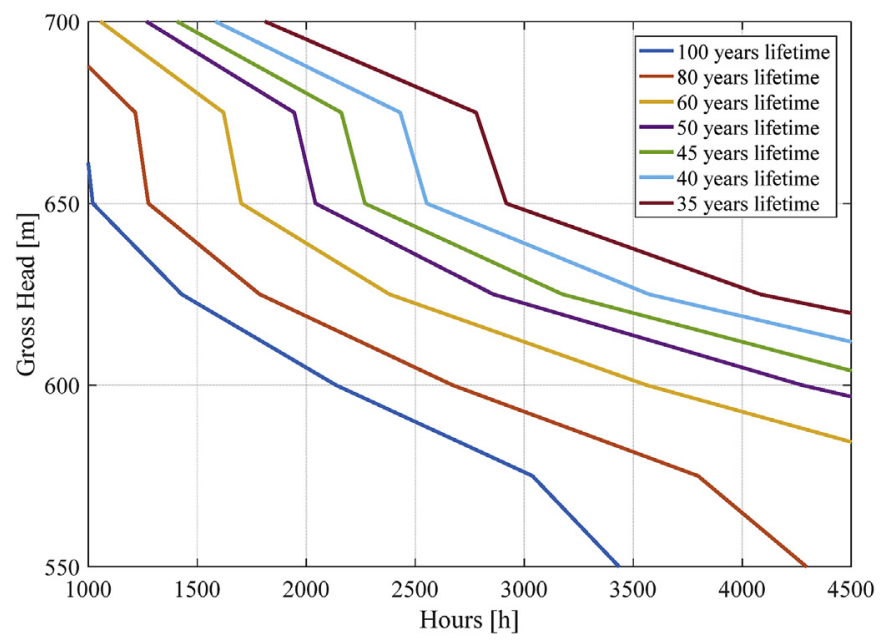

Fig. 12. Maximum number of hours per year in pumping mode at partial load to avoid fatigue damage for different gross heads and power plant lifetimes.
Table 4

Number of hours per year that the real PSPPs $1-7$ were assigned secondary regulation reserve in generating mode.

\begin{tabular}{lllllll}
\hline PSPP & 2010 & 2011 & 2012 & 2013 & 2014 & 2015 \\
\hline 1 & 2356 & 2088 & 2758 & 2884 & 3153 & 2765 \\
2 & 312 & 100 & 387 & 229 & 410 & 262 \\
3 & 366 & 137 & 470 & 344 & 470 & 306 \\
4 & 827 & 438 & 812 & 1253 & 2306 & 2579 \\
5 & 0 & 0 & 0 & 0 & 0 & 0 \\
6 & 101 & 33 & 108 & 49 & 104 & 112 \\
7 & 0 & 0 & 18 & 0 & 58 & 0 \\
\hline
\end{tabular}

Table 5

Number of hours per year that the theoretical PSPPs operate in pumping mode in the secondary regulation reserve market (hSM) and at partial load in pumping mode (hSM-pmin), i.e., between the minimum power pmin and pmin $+0.15 \cdot($ pmax-pmin)

\begin{tabular}{lllll}
\hline & PSPP & 2013 & 2014 & 2015 \\
\hline hSM & A & 3902 & 3736 & 3363 \\
& B & 4370 & 4128 & 3758 \\
\multirow{3}{*}{ hSM-pmin } & C & 3652 & 3497 & 3163 \\
& A & 1086 & 1043 & 676 \\
& B & 1221 & 1138 & 792 \\
& C & 1088 & 1025 & 722 \\
\hline
\end{tabular}

reproduces the pressure pulsations, as well as different power plant gross heads.

An equivalent tangential stress has been obtained from each set of Monte Carlo simulations (i.e. for each gross head) by the RFCM. The maximum number of stress cycles to avoid fatigue damage in the penstock has been computed for each considered gross head, by entering the fatigue curves of the Eurocode of Steel Structures with the corresponding equivalent tangential stress, and has been later translated into the maximum number of hours per year the PSPP can operate in pumping mode at partial load to avoid fatigue damage in the penstock for practical purposes.

By comparing the obtained maximum number of hours per year the PSPP can operate in pumping mode at partial load with the hours per year that real fixed-speed PSPPs and theoretical variablespeed PSPPs participate in the secondary regulation and operate at partial load in pumping mode, respectively, it can be concluded that fatigue damages are not likely to occur due to the participation of the PSPP in the secondary regulation service of the Spanish electric power system. Further research is necessary to accept or reject this conclusion in other power systems.

\section{Acknowledgements}

This work was supported by Ministerio de Economía, Industria y Competitividad, Gobierno de España under the project "Optimal operation and control of pumped-storage hydropower plants" of the National Scientific Research, Development and Technological Innovation Plan 2008-2011 [Ref. ENE2012-32207] and the University of Padova under the project "Analysis of unstable pump characteristics of pump turbines" [Ref. CPDA130025]. The authors gratefully acknowledge Roland Praus, Pierre Leroy and Laetitia Balarac (General Electric) for the provision of the technical data of the hydraulic and electrical equipment of the theoretical pumpedstorage power plants.

\section{Appendix}

The LPa has been checked by using expressions (28) and (29) [20-22]. 


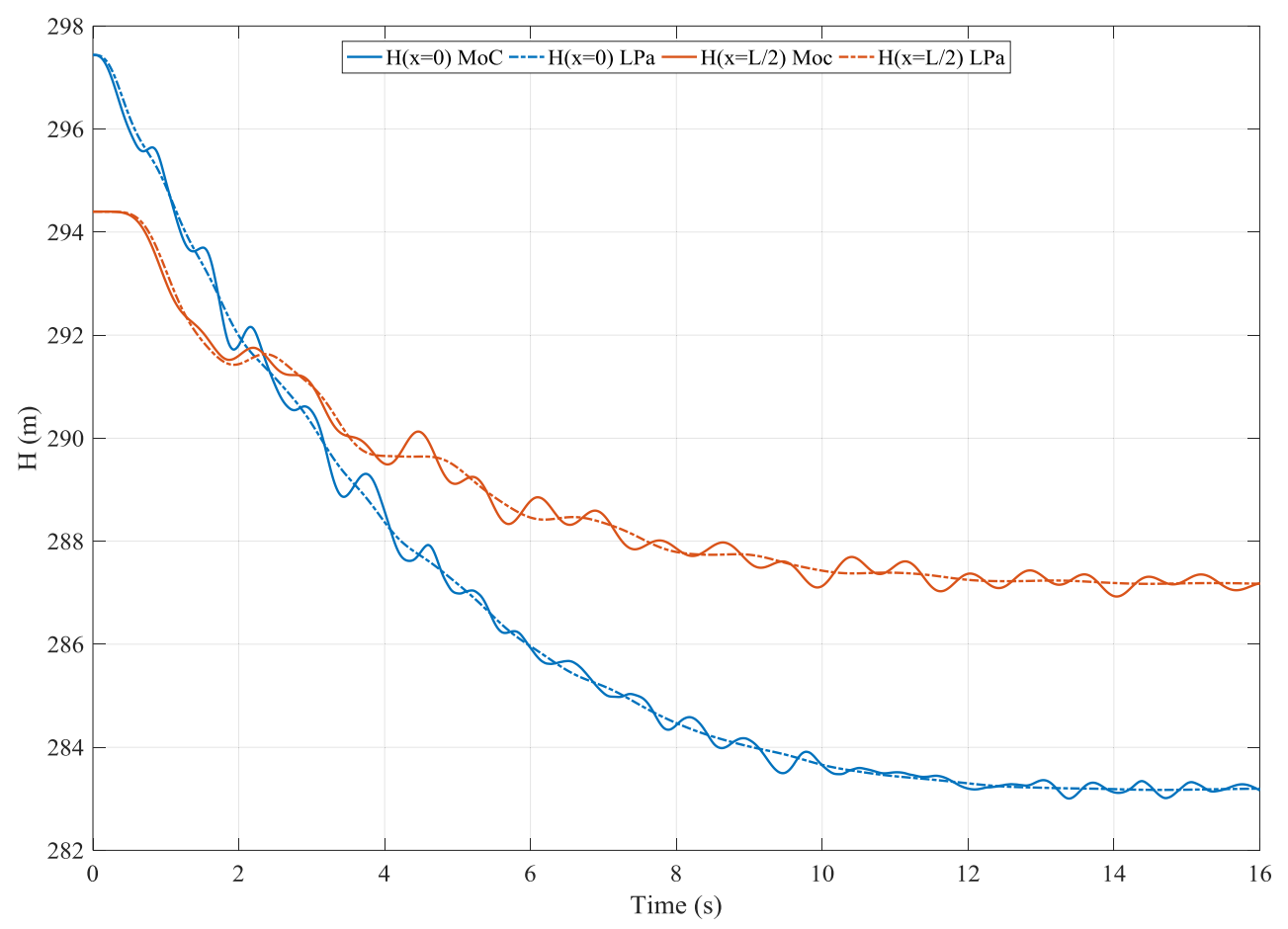

Fig. 13. Comparison between $\mathrm{MoC}$ and $\mathrm{LPa}$

$\frac{d q_{p, i}}{d t}=\frac{n_{t}+1}{T_{w}}\left(h_{i}-h_{i+1}-\frac{r}{2\left(n_{t}+1\right)} q_{p, i}\left|q_{i p, i}\right|\right)$

$\frac{d h_{i}}{d t}=n_{t} \frac{T_{w}}{T_{e}^{2}}\left(q_{p, i}-q_{p, i+1}\right)$

This method allows to obtain pressure value in each elastic element introduced along the conduit.

As it shown in Fig. 13, LPa acts as a filter of high frequency pressure signals neglecting theirs effects, while MoC is able to transmit these signals. Therefore, MoC is closer to reality than LPa and it has been selected to model water hammer effects.

\section{References}

[1] C. Nicolet, Y. Pannatier, B, Kawkabani, J. Simond, F. Avellan, Hydroelectric interactions with variable speed and fixed speed machines in pumping mode of operation, in: HYDRO Conference, 2011.

[2] P. Dorfler, M. Sick, A. Coutu, Flow-induced Pulsation and Vibration in Hydroelectric Machinery, Springer-Verlag, London, 2013.

[3] K. Bollinger, L. Nettleton, J. Gurney, Reducing the effect of penstock pressure pulsations on hydro electric plant power system stabilizer signals, IEEE Trans. Energy Convers. 8 (4) (1993) 628-631.

[4] Z. Zuo, S. Liu, Y. Sun, Y. Wu, Pressure fluctuations in the vaneless space of High-head pump-turbines-a review, Renew. Sustain. Energy Rev. 41 (2015) 965-974.

[5] A. Adamkowski, M. Lewandowski, S. Lewandowski, Evaluation of the Remaining Lifetime of Steel Penstocks in Hydropower Plants, 2010. Viena.

[6] J. Bulloch, A. Callagy, An detailed integrity assessment of a 25 MW hydroelectric power station penstock, Eng. Fail. Anal. 17 (2010) 387-393.

[7] C. Nicolet, R. Berthod, N. Ruchonnet, F. Avellan, Evaluation of Possible Penstock Fatigue Resulting from Secondary Control for the Grid, 2010.

[8] G. Martínez-Lucas, J. Pérez-Díaz, J. Sarasúa, G. Cavazzini, G. Pavesi, G. Ardizzon, Simulation model of a variable-speed pumped-storage power plant in unstable operating conditions in pumping mode, J. Phys. Conf. 813 (1) (2017) $1-6$.

[9] T. Kunz, Business Case Results about Potential Upgrade of Five EU Pumped Hydro Storage Plants to Variable Speed, 2015 eStorage project workshop, 2015 [Online]. Available: http://www.estorage-project.eu/documentlibrary. (Accessed 10 February 2017).
[10] M. Chazarra, J. Perez-Diaz, J. Garcia-Gonzalez, Optimal operation of variable speed pumped storage hydropower plants participating in secondary regulation reserve markets, in: 11th International Conference on the European Energy Market (EEM14), 2014.

[11] Y. Rebours, D. Kirschen, M. Trotignon, S. Rossignol, A survey of frequency and voltage control ancillary services - Part II: economic Features, IEEE Trans. Power Syst. 22 (1) (2007) 358-366.

[12] M. Chazarra, J.I. Pérez-Díaz, J. García-González, R. Praus, Economic viability of pumped-storage power plants participating in the secondary regulation service, Appl. Energy 216 (2018) 224-233.

[13] M. Chaudhry, Applied Hydraulic Transients, second ed., Van Nostrand, New York, 1987.

[14] S. Alligné, T. Maruzewski, T. Dinh, B. Wang, A. Fedorov, J. Iosfin, F. Avellan, Prediction of a Francis Turbine Prototype Full Load Instability from Investigations on the Reduced Scale Model, 2010.

[15] G. Cavazzini, A. Covi, G. Pavesi, G. Ardizzon, Analysis of the unstable behavior of a pump-turbine in turbine mode: fluid-dynamical and spectral characterization of the S-shape characteristic, J. Fluid Eng. 138 (2) (2015) 1-12.

[16] J. Yang, G. Pavesi, S. Yuan, G. Cavazzin, G. Ardizon, Experimental characterization of a pump-turbine in pump mode at hump instability region, J. Fluid Eng. 137 (5) (2015) 1-11.

[17] G. Pavesi, G. Cavazzin, G. Ardizzon, Numerical analysis of the transient behaviour of a variable speed pump-turbine during a pumping power reduction scenario, Energies 9 (7) (2016) 534.

[18] IEEE Working Group, Hydraulic turbine and turbine control models for system dynamic studies, IEEE Trans. Power Syst. 7 (1) (1992) 167-179.

[19] G. Pavesi, G. Cavazzini, G. Ardizzon, Experimental analyses and numerical simulation of a pump-turbine transient following process in pump mode, in: International Symposium on Transport Phenomena and Dynamics of Rotating Machinery, Hawaii, Honolulu, 2016.

[20] O. Souza Jr., N. Barberi, A. Santos, Study of hydraulic transients in hydropower plants through simulation of nonlinear model of penstock and hydraulic turbine model, IEEE Trans. Power Syst. 14 (4) (1999) 1269-1272.

[21] C. Nicolet, B. Greiveldinger, J.J. Hérou, B. Kawkabani, P. Allenbach, J.-J. Simond, F. Avellan, High-order modeling of hydraulic power plant in islanded power network, IEEE Trans. Power Syst. 22 (4) (2007) 1870-1880.

[22] G. Martínez-Lucas, J.I. Sarasúa, J.Á. Sánchez, J.R. Wilhemi, Power-frequency control of hydropower plants with long penstocks in isolated systems with wind generation, Renew. Energy 83 (2015) 245-255.

[23] M. Afshar, M. Rohani, Water hammer simulation by implicit method of characteristic, Int. J. Pres. Ves. Pip. 85 (2008) 851-859.

[24] A. Riasi, P. Tazraei, Numerical analysis of the hydraulic transient response in the presence of surge tanks and relief valves, Renew. Energy 107 (2017) $138-146$.

[25] GWEFR Cyf, Water Hammer and the Method of Characteristics, 2008 [Online]. Available: http://www.gwefr.co.uk/moc.pdf. (Accessed 3 March 2017). 
[26] Y. Wu, S. Liu, H. Dou, S. Wu, T. Chen, Numerical prediction and similarity study of pressure fluctuation in a prototype Kaplan turbine and the model turbine, Comput. Fluids 56 (2012) 128-142.

[27] J.L. Garcia Valdeolivas, Comportamiento Estructural de Tuberías Forzadas y Blindajes en Saltos Hidroeléctricos. Propuestas de Diseño y Cálculo, 2013. Tesis Doctoral, Madrid.

[28] L. Cuesta Diego, D. Vallarino, Aprovechamientos Hidroeléctricos, Ibergaceta Publicaciones, S.L:, Madrid, 2015.

[29] J. Wægter, Stress Range Histories and Rain Flow Counting, 2009 [Online]. [Accessed 16 march 2017].

[30] C. Amzallag, J. Gerey, J. Robert, J. Bahuaud, Standardization of the rainflow counting method for fatigue analysis, Int. J. Fatig. 16 (4) (1994) 287-293.

[31] G. Marsh, C. Wignall, P.R. Thies, N. Barltrop, A. Incecik, V. Venugopal, L. Johanning, Review and application of Rainflow residue processing techniques for accurate fatigue damage estimation, Int. J. Fatig. 82 (2016) 757-765.

[32] Eurocode EN 1993-1-9:2005, Eurocode 3: Design of Steel Structures - Part 1-
9: Fatigues, 2005.

[33] A. Evans, V. Strezov, T. Evans, Assessment of utility energy storage options for increased renewable energy penetration, Renew. Sustain. Energy 16 (2012) 4141-4147

[34] N. Pearre, L. Swan, Technoeconomic feasibility of grid storage: mapping electrical services and energy storage technologies, Appl. Energy 137 (2015) $501-510$.

[35] J. Deane, B. Ó-Gallachóir, E. McKeogh, Techno-economic review of existing and new pumped hydro energy storage plant, Renew. Sustain. Energy Rev. 14 (2010) 1293-1302.

[36] G. Ardizzon, G. Cavazzini, G. Pavesi, A new generation of small hydro and pumped-hydro power plants: advances and future challenges, Renew. Sustain. Energy Rev. 31 (2014) 746-761.

[37] H. Schlunegger, Pumping Efficiency, ABB Rev, 2014.

[38] T. Beyer [Online]. Available: http://www.hydroworld.com/articles/print/ volume-15/issue-1/articles/goldisthal-pumped-storage-plant-more-thanpower-production.html, 2007 [Accessed march 16 2017]. 